\title{
Enfermería Neurológica: un compromiso profesional e intelectual
}

\author{
Nursing, a professional commitment and intellectual
}

$\mathrm{E}$ n este año nuestra institución festeja su 50 aniversario de progreso y evolución, en los cuales se han plasmado los avances de las neurociencias. En este año también cumplimos doce años de editar la Revista de Enfermería Neurológica, así como el décimo aniversario de promover y congregar a investigadores en la reunión de investigación en enfermería. Al dar una mirada al pasado nos damos cuenta que lo que inició con una idea, poco a poco se ha ido conformando en un medio de comunicación y difusión entre profesionales de esta disciplina.

El llevar a cabo esta labor vislumbra un desafío a diario, pues el despertar la atención e interés del lector, el atraer su curiosidad como profesional enfermero, el conformar una idea principal y el establecer la logística de la creación de una revista en donde su contenido y su diseño, así como su formato es atractivo para adentrarte en ella.

Esta labor establece el compromiso profesional e intelectual que involucra a diferentes actores, entre ellos, el editor, mismo que cuenta con el apoyo del comité editorial que da forma y estructura a nuestra revista y, que a partir del profesional en el área de la salud interesado y comprometido tanto en compartir como en difundir sus ideas, preceptos, y nuevos conocimientos establece entre el editor e investigador un vínculo profesional que hace que se fortalezca el quehacer fundamental de la revista.

El hacer que ésta sea una publicación que se divulgue y cumpla su cometido como medio de difusión y transformación a profesionistas, estudiantes e interesados en el área ha sido, en la última década, el enfoque de las mujeres visionarias, entre las que se encuentran la enfermera neurológa, Hor- tensia Loza Vidal, Fundadora de la Revista de Enfermería Neurológica y las editoras, que por diferentes etapas, dieron cimientos y directriz a lo que es hoy nuestra revista, entre ellas la Licenciada Nidia Coronado García, MEE. Araceli Sánchez Ramos y MEE. María Guadalupe Nava Galán, profesionistas comprometidas del devenir y porvenir de los avances de la Revista de Enfermería Neurológica.

Es a bien considerar que como toda publicación, ésta debe contar con elementos de innovación que impriman el interés del profesional, en donde el acervo cultural y el cúmulo de conocimientos aunado con la experiencia en el área de las neurociencias como en el cuidado especializado, den cauce a su realización, así como el motivar e incentivar a las nuevas generaciones de enfermeros e involucrar a profesionistas que día a día aportan grandes enseñanzas a la enfermería. Es aquí donde se centra la función especial de la revista, la cual es atraer al personal profesional que ya ejerce profesionalmente y que cuenta con un bagaje de conocimientos invaluable, aunado a ello su experiencia profesional y, donde como grupo investigador en enfermería, vislumbra la incorporación a mediano plazo. El saber que, si bien la investigación como la matemática es considerada como ciencia elitista, esta percepción debe ser modificada, inicialmente desde la perspectiva de la instrucción, la enseñanza y la inclusión, y en este punto al incluirte ya formas parte, fomentando una relación cordial y benéfica para incursionar a una de las funciones esenciales del profesional enfermero, que es la investigación en enfermería.

MCE. Angélica Gpe. Dávalos-Alcázar 